\title{
GRUNDTVIGS GEDANKEN ÜBER CHRISTENTUM UND VOLK
}

A usführungen a u der ökumenischen Tagung a uf Lis elund, Ma i 1952 .

\section{Von Henning Høirup.}

Die Hauptgrundlage für Grundtvigs Auffassung vom Verhältnis zwischen den Völkern und dem Christentum ist die biblische Heilsgeschichte. Die einfachste Einführung in seine leitenden Gedanken ergibt sich deshalb durch einen kurzen Umriss seiner Anschauung vom »Hauptvolk der Geschichte«, Israel, »dem wichtigsten und merkwürdigsten Volk der Welt ( $\left.{ }^{1}\right)$.

Die ganze Heilsgeschichte ist nach Grundtvigs Anschauung als Gottes Verwirklichung der Verheissung an Abram - Verwirklichung unter ständigem Widerstand -: »Ich will dich zu einem grossen Volke machen .... und in dir sollen gesegnet werden alle Volksstämme auf Erden« (Gen. 12,2-3), zu betrachten. In Agypten wuchsen die Juden »von einer Familie bis zu einem ganzen Volk heran $\ll^{2}$ ), und in der Wüste erhielt das Gottesvolk das Gesetz, wodurch es für Gottes volle Offenbarung in der Fülle der Zeit vorbereitet wurde:

Kun hvor Loven havde lynet, Skiænket var og skærpet Synet For Guds Naades Sommersol ${ }^{3}$ ).

(Nur wo das Gesetz unter Blitz und Donner geoffenbart worden war, war der Blick geschenkt und geschärft für die Sommersonne der Gnade Gottes.)

1) Diese Ausdrücke stammen aus seinem grossen bibeltheologischen Jugendwerk »Kort Begreb af Verdens Krønike« (Kurzer Inbegriff der Weltchronik), 1814.

2) Nik. Fred. Sev. Grundtvigs Udvalgte Skrifter ved Holger Begtrup (zitiert als U S) II. Bd., S. 60 und N. F. S. Grundtvig: Krønnike-Riim, 3. Udg. 1875 , XLII.

3) N. F. S. Grundtvig: Christenhedens Syvstjerne. 1860, S. 8. 
Gott schuf sich erst ein Volk, das er durch gemeinsame Muttersprache und gemeinsame Geschichte miteinander verband; diesem auserwählten Volk offenbarte er sich. Aus »einer eigenwilligen Horde $\ll^{4}$ ) wurde ein Jahwe-Volk geformt; es wird erzogen und bereitet teils durch die volkliche Gemeinschaft, deren Leitstern der Gottespakt (das Gesetz) ist, teils durch die Muttersprache, die immer besser dazu ausgestaltet wird, Gottes Gnadenwillen zu verlebendigen, wie wir es sowohl in der Dichtung Israels als auch bei den Propheten sehen. In dieser Weise war alles in Palästina »dazu eingerichtet, das Volkstum ${ }^{5}$ ) zu erhalten und zu stärken«. Als Israels Volkstum dessenungeachtet in tötliche Erstarrung herabgesunken war, wurde es durch Johannes den Täufer wunderbar von neuem erweckt, bevor Christus kam; denn er wendete ja »das Herz der Kinder den Vätern und das Herz der Eltern den Kindern zu«, um dem Herrn den Weg zu bahnen und ihm ein »wohlbereitetes Volk« zu schaffen.

Das jüdische Volkstum, Israels volkhafte Eigentümlichkeit, wurde der Boden für die christliche Offenbarung. Das Wort wurde Jude, nicht »Mensch im allgemeinen«. Die Erwählung dieses Volkes, seine Erziehung unter dem Bundespakt und seine Bildersprache sind die Voraussetzung für Christi Inkarnation. Daher sagt Christus: »Das Heil kommt von den Juden« (Ev. Joh. 4, 22). Es ist nun charakteristisch für Grundtvig als Kirchenhistoriker, dass er das spätere Verhältnis des Christentums zu den verschiedenen Völkern im Lichte der Geschichte Israels betrachtet. Ohne die Sonderstellung Israels zu leugnen, behauptet er, dass Gott nicht aufhört, sich Völker $z u$ bereiten und zu erziehen, bei denen Christus zu Gast kommen kann. Was das Neue Testament von Johannes dem Täufer und das Alte von dem Elias sagt, der kommen sollte (Maleachi 4,6), das ist 》gerade des Volks-Engels, des guten Volks-Geistes Werk unter allen Himmelsstrichen, ebensowie bei Israel« (Predigt zum 3. Sonntag im Advent 1846). Ebensowie die christliche Offenbarung in ein besonderes Verhältnis zum jüdischen Volk trat, hat sie späterhin versucht, sich mit dem von Gott geschaffenen Sondercharakter jeder Völkerschaft zu vermählen. In seinem kirchlichen Sagasang: »Christenhedens Syvstjerne« (Das Siebengestirn der Christenheit) 1860, sagt Grundtvig, dass das seinem Überblick über die Kirchengeschichte Eigentümliche darin besteht, »dass das Christen-Leben ganz und

4) U S VI. Bd., S. 109.

5) »Folkeligheden«, worunter bei Grundtvig immer dasjenige zu verstehen ist, dem ein Volk nach Gottes Schöpferwillen gleichen (»ligne«) und das es durch die Eigenart seines Volkslebens ausdrücken soll. 
gar als geistiges Volksleben angesehen wird, das in lebendiger Wechselwirkung steht mit der eigentümlichen Entwicklung und Muttersprache aller der Haupt-Völker, bei welchen sich das Christen-Leben in christlichem Bekenntnis, Verkündigung und Lobgesang geoffenbart hat, und dass diese Wechselwirkung sowohl der Grund für den seltsam verwickelten Lebenslauf des Christenvolkes als auch der Hauptschlüssel für alle sogenannten christlichen Staatskirchen mit all ihrem Wirrwarr ist.« Grundtvig war zu dieser Auffassung durch seine aus den Quellen geschöpfte Kenntnis der älteren christlichen Dichtung (insbesondere der griechischen, römischen und angelsächsischen) gekommen. Man beachte, dass er gleichzeitig damit, dass er dafür eintritt, dass das Christentum in äusserst verschiedene volkliche Tracht gekleidet wird, einen offenen Blick für die Gefahr hat, dass das Volkstum über das Christliche (im Zwang der Staatskirchen) die Herrschaft gewinnt und damit die volle gegenseitige Freiheit aufhebt.

》Das Christen-Volk« (die heilige, allgemeine Gemeinde) ist Jesu Christi Leib zu allen Zeiten und in allen Völkerschaften; seine drei deutlichsten »Lebenszeichen«: christliches Bekenntnis, Verkündigung und Lobgesang, können indessen niemals reiner, wärmer oder klarer sein als die Muttersprache der Völker, die das Evangelium zu seiner Lebensäusserung leiht. Deshalb muss »das lebendige Christentum immer volkhaft (folkelig) sein und kann nur in dem Grade sich klären, wie Volk und Muttersprache christlich werden; denn wohl können wir uns unsere Muttersprache auf den feurigen Zungen des Heiligen Geistes weit mehr christlich entwickelt denken als auf unsern eigenen, aber dann verstehen wir doch nicht die an uns gerichtete Sprache des Geistes. Dies, dass es nur das Reden in der Muttersprache ist, das uns geistig zu Herzen geht, und dass daher die feurigen Zungen des Geistes am grossen Pfingsttage die Muttersprache aller Zuhörer sprachen und daher das lebendige Christentum keine eigene Sprache mit sich bringt, sondern die Muttersprache jedes Volkes leiht, bei dem es zu Gast kommt, das ist bisher in der Kirchengeschichte kaum bemerkt worden, aber daher ist sie auch unverständlich gewesen« (aus der Vorrede zum 》Siebengestirn der Christenheit«).

Dichterisch hat Grundtvig dieser seiner Anschauung von der Wechselwirkung zwischen dem Volklichen und dem Christlichen Ausdruck gegeben in vielen Kirchenliedern, z. B. in folgendem »Var I ikke Galilæer« (Wart ihr nicht Galiläer), wo es von 》Palästinas Apostelschar « heisst, dass ihr Wort ständig lebendig ist, obgleich ihre Sprache starb: 
Paaskemorgen, Pinsedagen.

Ikkun de forklare Sagen.

Gav jer alle Tungers Aand, Aanden, som kan alt udvirke, Som i Jesu Kristi Kirke Løser alle Tungebaand. - -

(Ostermorgen, Tag der Pfingsten, nur sie erklären die Lebenskraft, gaben euch aller Zungen Geist, den Geist, der alles wirken kann, der in Jesu Christi Kirche alles löst, was Zungen bindet. - -
Modersmaalet dybt sig bøjer,

Let og lifligt det sig føjer

Efter Herrens Tankegang;

Yndigt selv, men blødt derefter, Laaner Aand og Ild og Kræfter Det af Zions Heltesang ${ }^{\beta}$ ).

Die Muttersprache bückt sich tief, leicht und lieblich fügt sie sich nach des Herrn Gedankengang; selbst anmutig, doch sanft darauf, leiht sie Geist und Feuer und Kräfte von Zions Heldensang.)

In starkem Gegensatz $z u$ der individualistischen und idealistischen Tendenz seiner Zeit, die in der lutherischen Kirche dazu führte, den Nachdruck auf des einzelnen Christen Verhältnis zur Bibel und auf den Versuch zu legen, aus ihr eine christliche Ideologie $z \mathrm{u}$ exzerpieren, betont Grundtvig, dass das christliche Leben ein Christus-Leben ist, $d$. h. ein Leben in dem Volk, in das er uns durch die Taufe einverleibte, die Kirche, wo sein Geist uns »einsmacht mit unserm Herrn und miteinander« (wie es in dem Kirchenlied »Kirken den er et gammelt Hus« (Kirche, du bist ein ewig Haus) heisst). Nur durch die Gemeinde können wir Christus begegnen, der durch Taufe und Abendmahl sein Bundesvolk schafft und erhält, ebensowie wir nur dadurch wahre Menschen werden können, dass wir im Leben unseres irdischen Volkes mitleben.

Der letzte Teil des Gedankenganges, der programmatisch so ausgedrückt werden kann: »Auf Erden findet man niemals Menschentum ohne Volkstum $\left.\ll^{7}\right)$, bedeutet, dass jede Unechtheit und Unverantwortlichkeit in dem menschlichen Leben, zu dem uns Gott, um es in unserm Volk zu leben, geschaffen hat, unsere Aneignung des Evangeliums verfälscht:

Er os tomme Ord og Lyde eget Folk og Fædres Land, veed vi ej, hvad de betyde mer end Mængde, Muld og Strand, Tant er og hvert Ord, vi tale, om Guds Riges Bjerg og Dale, om Guds Folk og Menighed.
Føler ej vi i vort Hjerte, vi oprandt af Gude- $\mathbb{E t}$, ej vi føle kan med Smerte, at vi arted os kun slet, kun med Spot det Ord vi møde, at genløse og genføde Gud os vil som sine Børn ${ }^{8}$ ).

6) Salmer og aandelige Sange af Nik. Fred. Sev. Grundtvig Bd. I, 4. Udg. 1883 , S. 67-69.

7) U S Bd. IX, S. 86.

8) Christenhedens Syvstjerne, 1860, S. 173. 
(Sind uns eignes Volk und Land der Väter

leere Worte, leere Laute, wissen wir nicht, was sie bedeuten mehr als Menge, Fruchterde und

Strand, so ist Tand auch jedes Wort, das wir sagen von Bergen und Tälern des Reiches Gottes, von Gottes Volk und Gemeinde.
Fühlen wir nicht in unserm Herzen dass wir göttlichen Geschlechts und Ursprungs sind, dann können wir nicht mit Schmerzen fühlen, dass wir unser Leben nur schlecht führten, dann begegnen wir dem Worte nur mit Spott, dass Gott uns als seine Kinder erlöst und der Widergeburt teilhaftig werden lässt.)

Der Gedankengang kann folgendermassen wiedergegeben werden: Man wird »Mensch« dadurch, dass man in und mit seinem Volk lebt, unter dem Segen und der Verantwortung der Gemeinschaft, nicht dadurch, dass man als 》Weltbürger《 sich von seinem Volk losreisst, sondern dadurch, dass man sich zu dessen Erbe auch dessen Schuld - bekennt. Das Werk des Gesetzes und Johannes des Täufers muss ständig geschehen: die Erziehung bereiteter Menschen, die unlöslich unter dem Gesetz der Liebe miteinander verbunden sind. In dem Sinne kann Grundtvig zu seinen Landsleuten sagen: »Zuerst müssen wir Dänen sein«, nicht weil uns das Dänentum allwissend oder selig macht, sondern weil nur der, der im menschlichen Leben »aus der Wahrheit ist《 (Ev. Joh. 18, 37), eine menschliche oder eine christliche Botschaft hören kann. Dasselbe gilt selbstverständlich für jedes Volk.

Grundtvigs Schul- und Erziehungsgedanken entspringen aus dieser »volklichen« Grundschau. Er macht oft und ausdrücklich darauf aufmerksam, dass keine Nation, wie weit sie auch im volklichen Bildungsprozess gelangt, sich dadurch das Christentum verdient oder einen Anspruch darauf erwirbt, vielmehr sei es allezeit Gottes freies und unverdientes Geschenk. Aber es besteht die Analogie zwischen dem Mensch-Werden und dem Christ-Werden, dass man keines von beiden aus sich selbst oder für sich selbst wird, sondern nur dadurch, dass man einerseits in seinem Volke lebt, an es gebunden in Schuld und Dienst, und andrerseits in das Christenvolk, in Christi Leib und Leben, aufgenommen wird. An diesem Punkte trennt sich Grundtvigs gesamte christliche Denkweise in entscheidender Weise von Søren Kierkegaards Individualismus. Für Kierkegaard ist die »Gemeinde«, wenn er sie ein seltenes Mal sensu bono erwähnt, nicht beheimatet auf Erden, sondern gehört in die Ewigkeit. Eine solche Auffassung schliesst nach Grundtvigs Meinung die absolute Aufhebung der Möglichkeit der Erlösung in sich. 
Ohne eine Gemeinde »in der Zeit« keine Gemeinde »in der Ewigkeit«. Ohne eine Gemeinde keine Erlösung. Denn wo kein Leib ist, kann kein Glied leben (vergl. mein Buch: Grundtvigs Syn paa Tro og Erkendelse (Grundtvigs Anschauung von Glauben und Erkenntnis), 1949, S. 322).

Grundtvigs Anschauung vom Verhältnis zwischen Christentum und Volk findet ihren eigenartigsten Ausdruck in seinen Gedichten und Kirchenliedern, die fast nie individualistisch sind, sondern im Gegenteil davon ausgehen, dass die Existenz des einzelnen als Christen nur möglich ist als Glied des Gottesvolkes, des neuen Bundes Gemeinschaft in Gottes Erlösertaten. Ich verweise auf Kirchenlieder wie »Lyksaligt det Folk, som har Øre for Klang / herovenfra!« (Glückselig das Volk, das Ohren hat für den Klang / von oben her!) oder:

Stiftet Guds Søn har paa Jorden et aandeligt Rige, skaber og danner et kongeligt Folk sig tillige -

(Gestiftet hat Gottes Sohn hier auf Erden ein geistiges Reich, er schafft und bildet sich ein königliches Volk zugleich -).

Charakteristisch für seine an Andeutungen reiche Bildersprache mit den weiten Perspektiven, die in Prosa fast nicht wiedergegeben werden kann, ist sein Kirchenlied:
Alle mine Kilder skal være hos Dig!
Det var Guds-Ordet i gamle Dage
Til det Folkefærd uden Mage, som bar paa vor Herres Moder hos sig.
(All meine Quellen sind in Dir!
Das war das Gottes-Wort in alten Tagen
an das unvergleichliche Volk,
in dem die Mutter unseres Herrn geboren wurde).

In den folgenden Strophen wird die Eingangszeile (vergl. Psalm $87,7)$ auf Christus und sodann auf die Taufe, das Bad der Wiedergeburt, angewendet.

Da der Leser sich Grundtvigs Dichtung nur in demselben Grade aneignen kann, wie er mit der dänischen Sprache und dem dänischen Volksgeist vertraut ist, habe ich im wesentlichen seine lehrmässige Darstellung hier wiedergegeben, obgleich seine »Schau《 des Volklichen und Christlichen leicht verlorengeht oder entstellt wird, wenn man versucht, die darin gebrauchten poetischen Gleichnisse in Begriffe umzusetzen oder zu einer Ideologie zu verkürzen. $\mathrm{Zu}$ apologetischen und polemischen Zwecken hat er indessen oft selbst 
sich genötigt gesehen, das »Federkleid« des Dichters beiseitezulegen und seine »Schau« zum »Begriff« zu reduzieren. Ich benutze im folgenden zwei kurze Abhandlungen: »Volkstum und Christentum《 und »Über Volkstum und Dr. Rudelbach $\left.\aleph^{\vartheta}\right)$. In beiden geht er auf die Anklage ein, die schon Steffens wegen »Ultra-Danismus« und unzulässiger Vermischung des Volklichen und des Christlichen gegen ihn richtete.

Während seiner lebenslangen Beschäftigung mit dem Problem Kirche und Volk stand für Grundtvig selbstverständlich die Frage nach dem Verhältnis seines eigenen Volkes zum Christentum oft im Vordergrund. In dem Gedicht: Christi Kirche an Dänemark (1826, in der Dichtung »König Harald und Ansgar«) lässt Grundtvig die Kirche Christi sagen:

Det, hvormed jeg allerbedst

Kan for Verden mig betegne, $\mathrm{Er}$, at som en fremmed Gæst, Jeg indtræder alle Vegne,

Laaner Hus og lover ud

Løn derfor af Guders Gud ${ }^{10}$ ).
(Das, womit ich mich am allerbesten vor der Welt bezeichnen kann, Ist, dass ich als fremder Gast überall eintrete, das Haus leihe und Lohn dafür vom Allerhöchsten verspreche).

Die Kirche ist »der ganzen Erde Gast« und bringt die gleiche Botschaft allen Völkern, wenn sie den gekreuzigten und auferstandenen Christus als Gottes Sohn verkündigt. Auch zu Dänemark sagt die Kirche: „Som din Gjæst, jeg glad dig bød / Livets himmelfaldne Brød! (Als dein Gast bot ich dir froh das vom Himmel gekommene Brot des Lebens). Obschon das Feld nur langsam mit dem Evangelium zu besäen war und das Unkraut (die Quecken) schwer niederzuhalten war(en), versuchte Ansgar nicht, Dänemark mit Zwang zu christianisieren. Das entspricht dem ursprünglichen Verhältnis zwischen Volkstum und Christentum, das darin bestand, »dass das Christentum, selbst in Palästina, wo es entstand, geschweige denn in den heidnischen Ländern, wohin es verpflanzt wurde, sich zum Volkstum verhielt wie ein himmlischer Gast zu einem irdischen Heim, wohin er kam, nicht um sich dienen zu lassen, sondern um selbst zu dienen, und obgleich alle Spuren davon soweit möglich in den Tagen der Priester-Herrschaft (der Hierarchie) ausgelöscht

9) »Folkelighed og Christendom《 und »Om Folkeligheden og Dr. Rudelbach «, 1847, beide wieder abgedruckt in Begtrups Ausgabe von Grundtvigs Udvalgte Skrifter (Ausgewählte Schriften), Band IX, S. $80 \mathrm{ff}$. und $89 \mathrm{ff}$.

10) N. F. S. Grundtvigs Poetiske Skrifter, udg. af Svend Grundtvig, Bd. 5, S. 441. 
wurden, so bleibt doch voll und ganz das ursprüngliche Verhältnis das einzig rechte. $\left.\ll^{11}\right)$

Grundtvig freut sich daher darüber, dass das Christentum nicht als Gewalttäter nach Dänemark kam (durch Schwertmission, wie es die Karls des Grossen, Olaf Tryggvessons u. a. war), sondern »als ein schüchterner, wehrloser Klosterbruder«, der nur die taufte, die sich überreden liessen, an Jesus Christus zu glauben. Dieses freie Verhältnis zwischen Christentum und Volk wiederaufzurichten, das so schnell durch die katholische Hierarchie und später durch den Zwang der lutherischen Staatskirche zerstört wurde, war der Zweck des Grundtvigschen Kirchenkampfes. Jeder andere Einfluss als der, den das Christentum sich durch das Wort selbst bei einem Volk schaffen kann, ist vom Übel, und jeder Traum von einer herrschenden Kirche muss verabscheut werden: „Geistes-Freiheit und Volkstum sind das, was das Christentum, um in seinem (eigenen) Geist zu wirken, entweder vorfinden muss oder, wenn diese fehlen, sie schaffen muss«. Gemeinde und Volk müssen in einem vollkommen freien Verhältnis zueinander stehen.

Wie wir gesehen haben, gehen Grundtvigs Gedanken über Volkstum und Christentum von der Auffassung aus, dass »das ganze israelitische Volksleben die notwendige Voraussetzung für Christi Kommen ist«. Er behauptet ferner, dass es für jedes Volk gilt, sich seines »Volkstums« lebendig bewusst zu werden, weil es erst dann recht würdigen kann, was das Christentum anbietet und allen denen bietet, die Ohren haben, des Herrn Stimme zu hören. Sieht er zurück, muss er Gottes Weisheit ehren, »der so wunderbar alle Heidenvölker erzogen und entwickelt hat, die sich von ihm dazu erziehen und entwickeln lassen wollten, die Herrlichkeit Israels zu sehen « (vergl. Gen. 12, 2-3 und den Gedankengang auf Seite 73 der vorliegenden Abhandlung). Er preist Luther, der dadurch, dass er das Joch der Papstgeistlichkeit abschüttelte und die Muttersprache in Kirche und Bibel einführte, die zwei wichtigsten volklichen Bedingungen für das Wirken des Christentums bei uns schuf. Er wünscht, zwei andere Bedingungen dazuzufügen: bürgerliche Religionsfreiheit und »eine lebendige Betrachtung sowohl des Gotteswortes als auch der Menschen-Natur«. Was nun diese »Betrachtung« betrifft, muss eine kurze Darstellung hier versucht werden. Christus ist selbst das Gottes-Wort, das daher nie in unserer Verfügungsgewalt steht. »Was uns Gott gegeben hat (d. h. den Glauben, und den Geist und das Wort, die ihn tragen), ist immer in Gottes Hand«. Es ist nicht

11) U S Bd. IX, S. 81. 
Christentum, Christus nur geistig in sich aufzunehmen als das göttliche Vorbild von dem, wozu wir gereinigt werden sollen. Christentum ist, in Christus aufgenommen zu werden; auf keine andere Weise können der Sündenfall und die Macht der Sünde überwunden werden und das Glaubensverhältnis zu Gott hergestellt werden (wie es in Nordens Mythologi (Die Mythologie des Nordens), 1832, siehe Ausgewählte Schriften V, S. 402, entwickelt wird). Es heisst in seinem Kirchenlied: »Ønsker, lille! du at leve - (Wünscht du, Kind, zu leben -): »Kristus kun, som selv er Livet / Livets Ord har i sin Magt« (Nur Christus, der selbst das Leben ist / hat das Wort des Lebens in seiner Macht ${ }^{12}$ ).

Das Christentum ist also kein Faktor, mit dem wir in unsern kirchlichen und volkspädagogischen Bestrebungen operieren können. Aber ebensowenig wie die Freiheit des Evangeliums angetastet werden darf, darf die geistige Freiheit des Volkes geknechtet werden. 》Wo der Geist des Herrn ist, da ist Freiheit« (2. Kor. 3, 17). Dies wendet sich nicht nur gegen die katholische Kirche, die die Gemeinde unmündig macht (die Gemeinde hat keine Befugnis, sondern nur der Lehrstand der Kirche), sondern auch gegen die Auffassung, die im Protestantismus von »vielen sogenannten frommen Menschen« geteilt wird, die das menschliche und volkliche Leben als etwas ansehen, das das Christentum bekämpfen und abtöten muss. Nach Grundtvigs Ansicht ist das Christentum weit davon entfernt, das »Volkstum《 unterdrücken zu wollen, das es selbst erweckt hat und fördern will. Keine Nationalität verschafft jemand im geringsten das Heil als Verdienst; aber das Geschenk und die Aufgabe (Verantwortung) zu kennen, die uns in und mit dem Volk gegeben ist, in das wir hineingeschaffen sind, ist von entscheidender Bedeutung für unser Menschenleben. Demjenigen, der nicht in diesem Sinne »aus der Wahrheit ist« (der sich nicht als unter Gottes Schöpferwillen stehend erkennt), fehlt das Gehör, um damit zu hören, wenn das Evangelium von Christus ertönt: »Um lebendig zu erkennen, zu verstehen und uns ihn anzueignen, müssen wir alle dazu volklich erzogen, belebt und erleuchtet werden.«

Die christliche Offenbarung ist daher nicht (wie Dr. Rudelbach gegen Grundtvig behauptete) indifferent gegen alles Volkliche. Wenn auch das Christentum »sich vom Volklichen weder verändern, verbessern oder erfüllen lässt«, so ist das Volkstum keine gleichgültige Sache im Haushalt der göttlichen Gnade; in dem Falle wäre ja »die

${ }^{12}$ ) Salmer og aandelige Sange af Nik. Fred. Sev. Grundtvig, Bd. IV, 1875, S. 54 . 
Fleischwerdung des Sohnes Gottes ebenso überflüssig wie die ganze volkliche Erziehung und volkliche Bereitung Israels durch den Engel, der vor dem Angesicht des Herrn her ging, um ihm den Weg zu bahnen« (Hinweis auf Israels 》Volksengel«, siehe Ex. 23, $20 \mathrm{ff}$.). Grundtvig »weiss es sehr wohl, dass jede Nationalität (ebensowie jeder einzelne) sich von der Wahrheit abwenden und sich gegen sie verhärten kann, aber deshalb ist es ebenso gewiss, dass sie (die Nationalität) lebendig zur Stelle sein und sich bewusst werden muss, bevor sie in ein lebendiges Verhältnis zur geoffenbarten Wahrheit treten und sie wissentlich annehmen oder verwerfen kann«. Das Beste ist daher, dass wir die Augen aufmachen und sehen, 》was wir, als dänische oder deutsche, französische oder englische Menschen in ihren besten Kleidern sind, und es dann jedem im besonderen überlassen, . . . ob er sich an seinem Heidentum genügen lassen kann oder will, .... . oder ob er Lust und Bedürfnis nach dem ewigen Leben hat«.

$\mathrm{Zu}$ dieser »bürgerlichen Betrachtung« muss notwendigerweise die christliche Erleuchtung hinzugefügt werden, die ein Hauptpunkt der Theologie Grundtvigs ist, dass Christi Gemeinde, wodurch sein Wort und Leben zu uns kommt und uns in Christus einverleibt, allzeit geschaffen und erhalten wird vom Heiligen Geist, dem einzigen 》Statthalter《 im Reiche Gottes. Die Kirche Christi wird »nur von Schöpferhand« gebaut, wenn der Herr seinen Geist aussendet. Die Völker der Erde können in dieser Hinsicht positiv nichts anderes tun, als den besten Rahmen für eine freie Verkündigung des Christentums im Volke zu schaffen. Grundtvig gibt seiner Anschauung von der Kirche durch ein oft lächerlich gemachtes Bild (die 》Gastzimmer-Theorie«) Ausdruck, das von Jesu Wort inspiriert ist: »Wo ist das Gastzimmer, darin ich das Osterlamm mit meinen Jüngern essen möge? (Luk. 22, 11): Das Gottesvolk wird nur in einem irdischen Volk geschaffen, wenn der Geist des Herrn kommet; wir

\author{
bygge kun et Gæstekammer \\ til en himmelsk Altergang! \\ (bauen nur ein Gastzimmer \\ für ein himmlisches Abendmahl!) ${ }^{13}$ ).
}

Nur wenn ein Volk freiwillig Jesus Christus zu Gaste lädt und sein Evangelium und seine Gnadengaben entgegennimmt, erhält das Christentum die Möglichkeit, von innen her das Volksleben zu prägen.

13) Aus dem Kirchenlied »Tør end nogen ihukomme - (Salmer og aandelige Sange Bd. I, S. 45-48). 